\title{
Positive Electrospray Ion Trap Multistage Mass Spectrometric Fragmentation of Synthetic Analogs of Saccharide Part of Lipopolysaccharides of Vibrio cholerae 0:1
}

\author{
Vladimir Kováčik, Slavka Bekešová, and Igor Tvaroška \\ Institute of Chemistry, Slovak Academy of Sciences, Bratislava, Slovakia \\ Pavol Kováč \\ NIDDK, National Institute of Health, Bethesda, Maryland, USA
}

Oligosaccharides (mono- to hexamers) that mimic the terminal epitopes of O-antigens of Vibrio cholerae O:1, serotypes Ogawa and Inaba, have been studied by electrospray ion trap (ESI IT) mass spectrometry. Sodium or potassium-cationized adducts are characteristic ions under the conditions of ESI-MS analysis. The tentative pathways of fragmentation have been proven by multistage ion trap MS (MS $\left.{ }^{\mathrm{n}}, n=1-3\right)$. The predominant pathway of fragmentation of the oligomers is the neutral loss of monosaccharide residue shortening the length of the oligosaccharide. In this way, conversion of the Ogawa to Inaba fragments takes place under the conditions of measurement. ESI MS/MS provided sufficient information about molecular mass, the number of saccharide residues, and the structure of saccharides, about the $\mathrm{C}$ (4)-amide of 3-deoxy-L-glycero-tetronic acid (DGT) of the compounds investigated, and allows to distinguish between Ogawa and Inaba serotypes. (J Am Soc Mass Spectrom 2006, 17, 749-756) (c) 2006 American Society for Mass Spectrometry

\begin{abstract}
$\mathrm{C}$ holera is a serious enteric disease, which remains a persistent problem worldwide [1-4]. The most recent of the eight pandemics occurred in Peru and India/Bangladesh, in 1991 and 1992, respectively. The cholera problem is augmented by the fact that strains of Vibrio cholerae have become resistant to many antimicrobial agents. Systematic prevention of cholera by immunization has not yet been achieved because of a lack of an efficient protective vaccine. This work was carried out within studies of antigenic determinants of lipopolysaccharides (LPS) of Vibrio cholerae O:1. Previously, the monomeric models were studied by electron ionization mass spectrometry [5]. Here, we study synthetic mono- to hexasaccharides (Figure 1) that mimic the fragments of the $\mathrm{O}$-antigen of Ogawa and Inaba $O$-PS by electrospray mass spectrometry [6] in positive mode. The structure of $O$-specific polysaccharide (O-PS or O-antigen) of Vibrio cholerae O:1 consists of a relatively short chain of 4-amino-4,6-dideoxy$\alpha$-D-mannopyranose (perosamine), the amino group of which is acylated with 3-deoxy-L-glycero-tetronic acid (DGT). The O-PS of the Ogawa strain differs from that
\end{abstract}

Published online April 5, 2006

Address reprint requests to Dr. V. Kováčik, Institute of Chemistry, Slovak Academy of Sciences, Dúbravska cesta 9, 84538 Bratislava, Slovakia. E-mail: chemvkov@savba.sk of Inaba in that the upstream, terminal 4-acylated 4-amino-4,6-dideoxy- $\alpha$-D-mannopyranose residue in the O-PS of the Ogawa strain carries a methyl group at $\mathrm{O}-2$.

\section{Experimental}

The Ogawa and Inaba oligosaccharide models ${ }_{1-6} \mathrm{Og}$ and ${ }_{1-6}$ In (Figure 1), were synthesized as described previously [7-11] The purity of the substances was verified by MALDI-TOF MS and ${ }^{13} \mathrm{C}$ NMR spectroscopy. Molecular mass was determined on MALDI TOF IV (Shimadzu, Kratos Analytical, Manchester, UK) instrument. 2,5-Dihydroxy benzoic acid was used as a matrix. Ion acceleration voltage was $5 \mathrm{kV}$. Samples were irradiated by $337 \mathrm{~nm}$ photons from the nitrogen laser. Typically, 100 shots were summed into a single mass spectrum. ${ }^{13} \mathrm{C}$ NMR spectra were measured on Bruker Avance-DPX FT (300 MHz) instrument in deuteriochloroform.

Positive ion ESI MS ${ }^{1-5}$ were measured on Esquire 3000 ion-trap mass spectrometer (Bruker Daltonik, Bremen, Germany) equipped with an electrospray ionization source. One $\mathrm{mg}$ of the sample was dissolved in $1 \mathrm{ml}$ of acetonitrile/water 1:1. Sample solutions were introduced into the ion source at the flow rate of $3 \mu \mathrm{l} / \mathrm{min}$ via a metal capillary held at high voltage $(3.5 \mathrm{kV})$. Other 


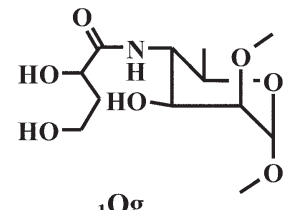

${ }_{1} \mathrm{Og}$

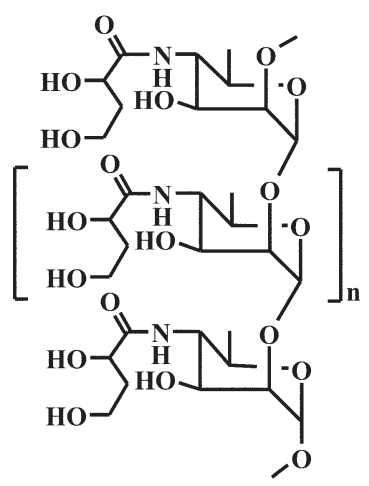

${ }_{2+n} \mathrm{Og} n=0-4$

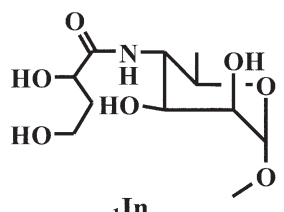

${ }_{1}$ In

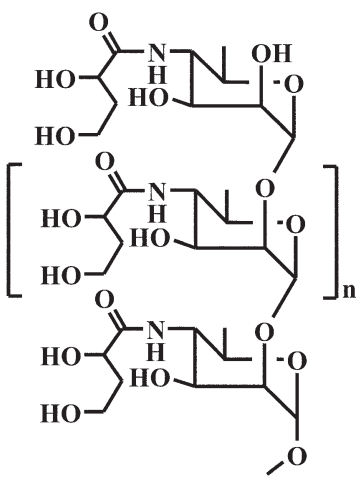

${ }_{2+n} \operatorname{In} n=0-4$
Figure 1. Compounds investigated.

instrument conditions were as follows: drying gas temperature, $250^{\circ} \mathrm{C}$; drying gas flow, $5 \mu \mathrm{l} / \mathrm{min}$; nebulizer pressure, 14 psi. Nitrogen was used as both nebulizing gas and drying gas. The nozzle-skimmer potential and octopole potential were modified and optimized before each experiment. For CID ESI MS measurement, a value of 0.95 was applied to all substances by way of fragmentation amplitude. Two or three measurements were run with every sample, if necessary.

The quantum chemical calculations were carried out using the Jaguar program [12] on QS8-2800 C computer [13]. The optimizations of the geometry were performed using the B3LYP density functional method [14] (DFT) with the standard $6-31 \mathrm{G}^{*}$ basis set. The geometries for a set of low-energy candidate structures for the monosaccharide $\left.{ }_{1} \mathbf{I n}\right)$ complexes with the sodium cation were fully optimized with no constraints on geometrical parameters. The final energies were obtained using the single point calculations at the B3LYP/6-311 $++\mathrm{G}^{* *}$ levels from the $6-31 G^{*}$ optimized geometry. Mass Frontier software [15] 4.0 (MF) was used to assist in the elucidation the fragmentation [16].

\section{Results and Discussion}

\section{Conformational Study}

The conformation of C(4) amide 3-deoxy-L-glycero-tetronic acid substituent NHDGT-C(4) influences stability of ${ }_{1}$ In conformations and formation of $\mathrm{Na}^{+}$complexes. Five torsional angles describe the conformation of the NHDGT-C(4) group (Table 1), namely $\chi_{1}=[C(3)-C(4)-$

Table 1. Schematic reperesentation of the (Z)-anti conformer of the ${ }_{1}$ In molecule and the labeling of the atoms. Selected torsional angles (deg) of ${ }_{1}$ In conformers and sodium complexes calculated at B3LYP/6-31G* level and the relative energy $\Delta E\left(\mathrm{kcal} \mathrm{mol}^{-1}\right)$ of conformers calculated using different basis sets

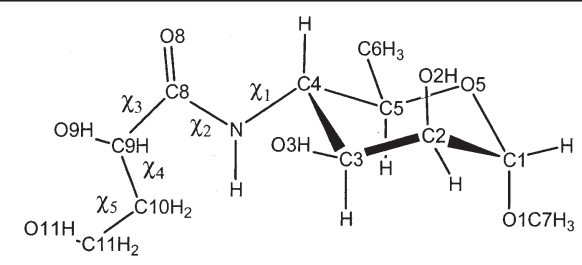

\begin{tabular}{|c|c|c|c|c|c|c|c|}
\hline & \multicolumn{5}{|c|}{ Torsional angle } & \multicolumn{2}{|c|}{$\Delta E$} \\
\hline & $\chi_{1}$ & $\chi_{2}$ & $\chi_{3}$ & $\chi_{4}$ & $\chi_{5}$ & $6-31 \mathrm{G} *$ & $6-311++\mathrm{G}^{* *}$ \\
\hline (Z)-anti & 112.5 & -168.2 & -97.4 & -175.8 & -71.8 & $0.00^{a}$ & $0.00^{\mathrm{b}}$ \\
\hline (Z)-syn & -62.9 & 161.1 & -102.1 & -177.6 & -72.0 & 1.42 & 2.05 \\
\hline$(E)-a n t i$ & 97.5 & 25.4 & -101.4 & -174.1 & -72.3 & 6.20 & 7.55 \\
\hline$(E)-s y n$ & -70.7 & -8.9 & -95.4 & $\begin{array}{l}-174.3 \\
(Z)-a n t i\end{array}$ & -73.1 & 12.02 & 12.81 \\
\hline $\mathrm{Na} 1$ & 92.9 & 174.3 & 28.5 & 169.3 & -86.6 & 10.47 & 9.37 \\
\hline $\mathrm{Na} 2$ & 87.5 & -164.6 & 21.5 & 168.1 & -74.9 & 11.20 & 12.09 \\
\hline $\mathrm{Na} 3$ & 88.2 & -163.6 & -17.6 & -175.7 & -59.4 & $0.00^{c}$ & $0.00^{d}$ \\
\hline $\mathrm{Na} 4$ & 98.1 & -175.0 & 34.2 & -177.9 & -61.8 & 5.55 & 3.52 \\
\hline $\mathrm{Na} 5$ & 94.5 & -161.2 & 64.4 & -174.1 & -74.2 & 10.51 & 8.54 \\
\hline $\mathrm{Na} 6$ & 69.8 & 172.1 & -130.2 & -171.0 & -59.7 & 7.31 & 6.94 \\
\hline $\mathrm{Na} 7$ & 130.1 & -174.1 & 51.9 & $(Z)-s y n$ & -87.3 & 29.87 & 25.51 \\
\hline $\mathrm{Na} 3$ & -58.5 & 171.7 & 79.3 & -174.5 & -57.2 & 6.22 & 4.20 \\
\hline $\mathrm{Na} 4$ & -55.8 & 174.9 & 80.0 & -176.4 & -60.0 & 6.12 & 4.12 \\
\hline $\mathrm{Na} 6$ & -81.6 & 172.0 & -123.8 & -175.7 & -62.2 & 14.38 & 11.11 \\
\hline
\end{tabular}

${ }^{\mathrm{a}} E=-1013.097183$ a.u.; ${ }^{\mathrm{b}} E=-1013.436271$ a.u.; ${ }^{\mathrm{c}} E=-1175.285486$ a.u.; ${ }^{\mathrm{d}} E=-1175.615952$ a.u. 

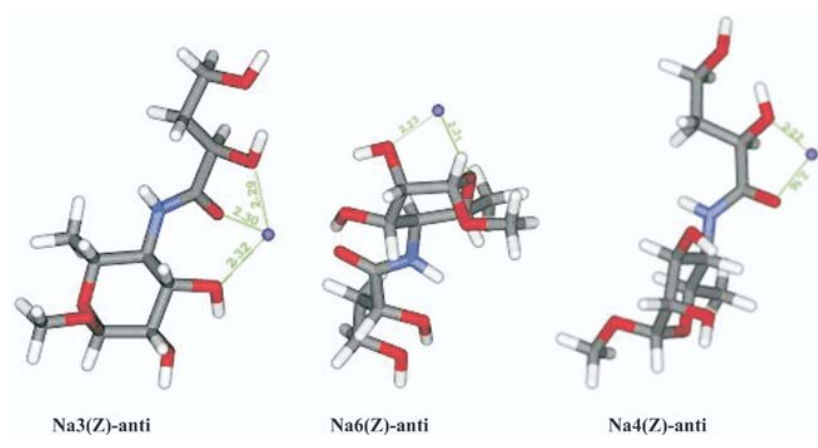

Figure 2. The B3LYP/6-31G* calculated structures of three preferred complexes for $(Z)$ - anti conformer.

$\mathrm{N}-\mathrm{C}(8)], \chi_{2}=[\mathrm{C}(4)-\mathrm{N}-\mathrm{C}(8)-\mathrm{C}(9)], \chi_{3}=[\mathrm{N}-\mathrm{C}(8)-\mathrm{C}(9)-$ $\mathrm{C}(10)], \chi_{4}=[\mathrm{C}(8)-\mathrm{C}(9)-\mathrm{C}(10)-\mathrm{C}(11)]$, and $\chi_{5}=[\mathrm{C}(9)-$ $\mathrm{C}(10)-\mathrm{C}(11)-\mathrm{O}(11)]$. The torsional angle around $\mathrm{C}(4)-\mathrm{N}$ bond $\left(\chi_{1}\right)$ may adopt either the antiperiplanar or synperiplanar arrangement relative to the $C(4)-N$ and $\mathrm{N}-\mathrm{C}(8)$ bonds. The four possible conformers are $(Z)-$ anti, (Z)-syn, (E)-anti, and (E)-syn.The initial structures of the (Z)-anti, (Z)-syn, (E)-anti, and (E)-syn conformers for ${ }_{1}$ In were built using the preferred ${ }^{4} C_{1}$ ring conformation and with conformations around three $\mathrm{C}-\mathrm{C}$ bonds $\left(\chi_{3}-\chi_{5}\right)$ in the antiperiplanar orientation. These four structures of ${ }_{1}$ In were optimized using fully relaxed calculations at the B3LYP /6-31G* level, and then the energy was calculated at the B3LYP/6-311 ++ $\mathrm{G}^{* *}$ level. The (Z)-anti conformer $\left(\chi_{1}=112.5^{\circ}\right.$ and $\chi_{2}=$ $\left.-168.2^{\circ}\right)$ is $2.05,7.55$, and $12.81 \mathrm{kcal} / \mathrm{mol}$ more stable than the (Z)-syn $\left(-62.9^{\circ}, 161.1^{\circ}\right),(E)$-anti $\left(97.5^{\circ}, 25.4^{\circ}\right)$, and $(E)$-syn $\left(-70.7^{\circ},-8.9^{\circ}\right)$ conformers, respectively. Orientation of the hydroxyl groups in all conformers is anti-clockwise with the $\mathrm{HO}(3)$ proton pointing to the $\mathrm{O}(2)$ oxygen and forming a hydrogen bond. The remaining part of the NHDGT-C(4) group adopts a similar conformation in all four conformers exhibiting $\mathrm{O}(9)-\mathrm{H}-\mathrm{O}(11)$ hydrogen bond. This is documented by the interval of values for torsional angles $\chi_{3}\left(-95^{\circ}-\right.$ $\left.-102^{\circ}\right), \chi_{4}\left(-174^{\circ}--178^{\circ}\right)$, and $\chi_{5}\left(-72^{\circ}--73^{\circ}\right)$, respectively. The calculated preference of the (Z)-anti conformer is in conformity with the experimental data on $\alpha$-d-glucopyranosides [17]. Therefore, the optimized structures of the (Z)-anti conformer was selected to generate the initial structures of $\mathrm{Na}^{+}$complexes positioning the sodium cation at seven different locations depicted in Figure 2. These structures were optimized in fully relaxed calculations.

The optimization at the B3LYP/6-31G* level led to seven (Z)-anti distinct minima. The values of the torsional angles $\chi_{1}-\chi_{5}$ together with the relative energies of the seven resulting complexes (Na1-Na7) are given in Table 1 . The relative binding energies calculated at the B3LYP/6-311 ++ $G^{* *} / / 6-31 G^{*}$ level are reported in Table 2 . The complexation of ${ }_{1}$ In with the sodium cation changes the conformation of the ${ }_{\mathbf{1}} \mathbf{I n}$. The most sensitive to this complexation is the orientation around the $C(8)-C(9)$ bond characterized by the $\chi_{3}$ torsional angle. This is reflected in a large interval (from $-130^{\circ}$ to $64^{\circ}$ ) of the $\chi_{3}$ values. It can be seen from the relative energy values in Table 2 that $\mathrm{Na} 3, \mathrm{Na} 4$, and $\mathrm{Na} 6$ complexes are the preferred ones. These three optimized complex structures are shown in Figure 2. To evaluate an influence of a conformation of the NHDGT-C(4) group on stability of complexes, we have calculated also the three preferred location of the sodium cation for the second

Table 2. Schematic reperesentation of seven starting locations (Nal-Na7) for the sodium complexes of ${ }_{1}$ In. Position of the sodium

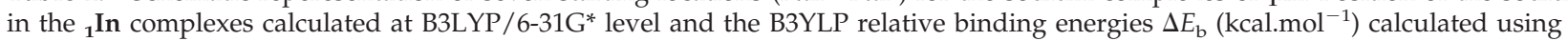
different basis sets

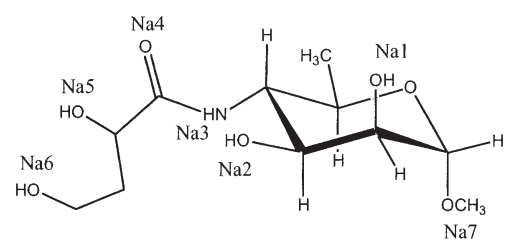

\begin{tabular}{|c|c|c|c|c|c|}
\hline \multirow[b]{2}{*}{ Conformer } & \multirow[b]{2}{*}{ Complex } & \multicolumn{2}{|c|}{$\mathrm{Na}^{+}$position } & \multicolumn{2}{|c|}{$\Delta E_{\mathrm{b}}{ }^{\mathrm{a}}$} \\
\hline & & Initial & Final & $6-31 G^{*}$ & $6-311+G^{* *}$ \\
\hline \multirow[t]{7}{*}{ (Z)-anti } & $\mathrm{Na} 1$ & $\mathrm{O} 2$ & 020308 & -56.72 & -48.43 \\
\hline & $\mathrm{Na} 2$ & $\mathrm{O} 3$ & 030809 & -55.99 & -45.71 \\
\hline & $\mathrm{Na} 3$ & $\mathrm{~N}$ & 030809 & -67.19 & -57.80 \\
\hline & $\mathrm{Na} 4$ & O8 & 0809 & -61.64 & -54.28 \\
\hline & $\mathrm{Na} 5$ & 09 & 09011 & -56.68 & -49.27 \\
\hline & $\mathrm{Na} 6$ & $\mathrm{O5}$ & $\mathrm{O} 2 \mathrm{O} 5$ & -59.88 & -50.86 \\
\hline & $\mathrm{Na} 7$ & 01 & $\mathrm{O} 2 \mathrm{O} 5$ & -37.32 & -32.29 \\
\hline \multirow[t]{3}{*}{ (Z)-syn } & $\mathrm{Na} 3$ & $\mathrm{~N}$ & 030809 & -62.39 & -55.65 \\
\hline & $\mathrm{Na} 4$ & $\mathrm{O} 8$ & 0809 & -62.48 & -55.73 \\
\hline & $\mathrm{Na} 6$ & O5 & $\mathrm{O} 2 \mathrm{O} 5$ & -54.23 & -48.73 \\
\hline
\end{tabular}

${ }^{\mathrm{a}} \Delta E=E_{\text {complex }}-E_{1 \mathrm{ln}}-E_{\mathrm{Na}+} ; E_{\mathrm{Na}+}\left(6-31 \mathrm{G}^{*}\right)=-162.081231$ a.u.; $\mathrm{E}_{\mathrm{Na}+}\left(6-311++\mathrm{G}^{* *}\right)=-162.081246$ a.u. 


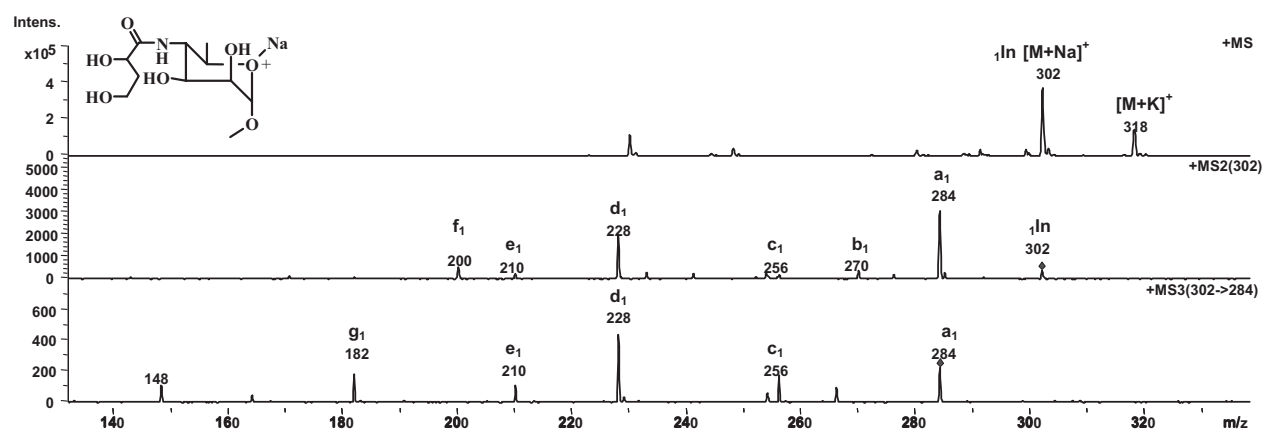

Figure 3. ESI IT multistage mass spectra of Inaba monomer ${ }_{1}$ In.

lowest energy conformers (Z)-syn. The results are shown in Tables 1 and 2. In $\mathrm{Na} 3$ and $\mathrm{Na} 4$ complexes, one of the oxygens coordinating the sodium cation is the carbonyl oxygen $\mathrm{O}(8)$ of the NDGT group. The lowest energy complex Na3 exhibits interactions of the sodium cation with two oxygen atoms, $\mathrm{O}(8)$ and $\mathrm{O}(9)$, whereas complexes $\mathrm{Na} 4$ and $\mathrm{Na} 6$ show interactions of sodium atom with three oxygens of ${ }_{1}$ In molecule. $\mathrm{Na}^{+}$ - O distances from 2.15 to $2.37 \AA$ are characteristic for the sodium complexes of ${ }_{1} \mathbf{I n}$. It is interesting to note that the nitrogen atom is not involved in the coordination of the sodium cation, although one of starting positions (Na3) was from the "N-location". In two Na2 and $\mathrm{Na} 3$ complexes, the same oxygen atoms are involved in coordination of sodium. However the structure of the resulting complex is different. The binding energy of these complexes decreases with an enlargement of basis set, e.g., for the complex $\mathrm{Na} 3$ decreases from $67.2 \mathrm{kcal} / \mathrm{mol}$ at the $6-31 \mathrm{G}^{*}$ level to $57.8 \mathrm{kcal} / \mathrm{mol}$ at the $6-311++G^{* *}$ level. We have observed the similar trend during our previous work [18].

\section{ESI-IT MS Study of Mass Spectrometric Fragmentation Rules of Basic Structural Units of LPS}

Fragmentation of monomeric substances ${ }_{1}$ In and ${ }_{1} \mathrm{Og}$ has been elucidated from the ESI IT multistage mass spectra. The aim of this work was to obtain tandem mass spectrometric fragmentation rules of basic structural units of the LPS. Examples of ion trap mass spectra $\mathrm{MS}^{1-3}$ obtained from ${ }_{1}$ In are shown in Figure 3. The tandem $\mathrm{MS}^{2}$ spectrum of the ${ }_{1} \mathrm{Og}$ monomer is presented in Table 3, which summarizes the ion trap MS data of all Ogawa compounds investigated. The Mass Frontier software has assisted in the formulation of the fragmentation mechanisms shown in the Scheme 1 . In the first route, a molecule of water is eliminated from the sodium-cationized molecule. The $\left[\mathrm{M}+\mathrm{Na}-\mathrm{H}_{2} \mathrm{O}\right]^{+}$ ions are denoted as a species. In the following steps, elimination of a molecule of ethene, carbon monoxide, water, or hydroxypropanal gives rise to the $\mathbf{c}, \mathbf{d}$, and $\mathbf{e}$ species, as proven by $\mathrm{MS}^{2}$ and $\mathrm{MS}^{3}$ measurements. The marked eliminations are formulated as products of decay of the adducts coordinated on the carbonyl oxygen of the NDGT group. The less energetic isomer, the adduct with the Na cation in coordination to hemiacetal oxygen atom is supposed. In the less favored route, the elimination of molecule of methanol from [M $+\mathrm{Na}]^{+}$adducts takes place. The presence of a methoxy group at the $\mathrm{C}(2)$ position in ${ }_{1} \mathrm{Og}$ reflects the shift of $\mathrm{m} / \mathrm{z}$ values of the respective ions by $14 \mathrm{u}$. The fragmentation of hemi-acetal coordinated adducts involves elimination of a molecule of $\alpha$-hydroxy- $\gamma$-butyrolactone ( $f$ and $\mathrm{g}$ fragments) giving rise to sodium ions of the 4-amino mannopyranoside type. We are not able to provide a straightforward explanation for the ion at $\mathrm{m} / \mathrm{z} 148$ in the $\mathrm{MS}^{3}$ spectrum of ${ }_{\mathbf{1}}$ In (Figure 3). Fragmentation of di- to hexa-oligomers was elucidated in the same manner (Figures 4 and 5, Tables 3 and 4) as that applied to the monomer. In the spectra of the dimer, the cleavage of these ions results in formation of the monomer, having the same structure as the Inaba monomer, with the hydroxyl group at the C(2) position. Similar shortening of the oligosaccharide chain is observed also for the higher oligomers. In the spectrum of the trimer, these ions represent two species, the dimeric and monomeric Inaba type ions. In the spectrum of the tetramer, two similar ions, the trimeric and dimeric, are again present (Figure 4). On the other hand, the pentamer spectrum (Figure 5) shows three intense species: tetra-, tri- and dimer. And finally in the spectrum ESI IT of the hexamer, four shorter species containing Inaba units are present. The intensity of monomer ${ }_{1}$ In fragment is negligibly. A comparison of the ESI MS ${ }^{n}$ spectra of the oligomers of Ogawa and Inaba types confirms that the leaving residue in the first step of the chain-shortening pathway is the upstreaming mannose unit with the $C(2)$ hydroxyl or methoxyl C-2 group of the oligomer. Formally the chain shortening pathways correspond to those resulting in $\mathrm{Y}$ ions from oligosaccharides described by Domon and Costello [19] and others. The fragmentation of hemi-acetal coordinated adducts involves the elimination of molecule of $\alpha$-hydroxy- $\gamma$ butyrolactone (f and $g$ fragments) in the $\mathrm{MS}^{2}$ spectra, giving rise to sodium adducts of the 4-amino mannopyranoside type. In the $\mathrm{MS}^{3}$ and higher multistage spectra, the elimination of other molecules of $\alpha$-hydroxy- $\gamma$ butyrolactone (minus $102 \mathrm{mu}$ ) or other species also from product ions was observed. Example routes in 
Table 3. The ion abundances in ESI IT tandem mass spectra of $[\mathrm{M}+\mathrm{Na}]^{+}$ions of LPS models, serotype Ogawa ${ }_{1} \mathrm{Og}_{-6} \mathrm{Og}$

\begin{tabular}{|c|c|c|c|c|c|c|c|}
\hline \multicolumn{8}{|c|}{ Number of monosaccharide residues* } \\
\hline \multirow[b]{2}{*}[\mathrm{M}+\mathrm{Na}]{$^{*}$} & \multirow[b]{2}{*}{$m / z$} & \multicolumn{6}{|c|}{ Abundance [\%] } \\
\hline & & 1 & 2 & 3 & 4 & 5 & 6 \\
\hline${ }_{6} \mathrm{Og}$ & 1551 & - & - & - & - & - & 15 \\
\hline$a_{60 g}$ & 1533 & - & - & - & - & - & 100 \\
\hline $\mathrm{c}_{60 \mathrm{~g}}$ & 1505 & - & - & - & - & - & 19 \\
\hline$d_{60 g}$ & 1477 & - & - & - & - & - & 38 \\
\hline$f_{60 g}$ & 1449 & - & - & - & - & - & 60 \\
\hline${ }_{5} \mathrm{Og}$ & 1304 & - & - & - & - & 20 & - \\
\hline$a_{50 g}$ & 1286 & - & - & - & - & 58 & - \\
\hline $\mathrm{c}_{5 \mathrm{Og}}$ & 1258 & - & - & - & - & 25 & - \\
\hline$d_{50 g}$ & 1230 & - & - & - & - & 49 & - \\
\hline$e_{50 g}$ & 1212 & - & - & - & - & 25 & - \\
\hline$f_{50 g}$ & 1202 & - & - & - & - & 75 & - \\
\hline$h_{50 g}$ & 1184 & - & - & - & - & 20 & - \\
\hline${ }_{5} \ln$ & 1290 & - & - & - & - & - & 45 \\
\hline${ }_{4} \mathrm{Og}$ & 1057 & - & - & - & 31 & - & - \\
\hline$a_{4 O g}$ & 1039 & - & - & - & 27 & - & - \\
\hline $\mathrm{c}_{4 \mathrm{Og}}$ & 1011 & - & - & - & 10 & - & - \\
\hline$d_{4 O g}$ & 983 & - & - & - & 28 & - & - \\
\hline $\mathrm{e}_{4 \mathrm{Og}}$ & 965 & - & - & - & 21 & - & - \\
\hline $\mathrm{f}_{4 \mathrm{Og}}$ & 955 & - & - & - & 31 & - & - \\
\hline $\mathrm{h}_{4 \mathrm{Og}}$ & 923 & - & - & - & 13 & - & - \\
\hline${ }_{4} \ln$ & 1043 & - & - & - & - & 57 & 54 \\
\hline$a_{4 \mid n}$ & 1025 & - & - & - & - & 10 & 15 \\
\hline $\mathrm{c}_{4 \mathrm{ln}}$ & 997 & - & - & - & - & - & 5 \\
\hline$d_{4 \mid n}$ & 969 & - & - & - & - & - & 13 \\
\hline$e_{4 \mid n}$ & 951 & - & - & - & - & 9 & - \\
\hline \multirow[t]{2}{*}{$f_{4 l n}$} & 941 & - & - & - & - & 8 & - \\
\hline & 888 & - & - & - & 71 & - & - \\
\hline${ }_{3} \mathrm{Og}$ & 810 & - & - & 5 & - & - & - \\
\hline$a_{30 g}$ & 792 & - & - & 21 & - & - & - \\
\hline $\mathrm{c}_{3 \mathrm{Og}}$ & 764 & - & - & 9 & - & - & - \\
\hline$d_{3 O g}$ & 736 & - & - & 18 & - & - & - \\
\hline $\mathrm{f}_{3 \mathrm{Og}}$ & 708 & - & - & 24 & - & - & - \\
\hline $3_{3} \ln$ & 796 & - & - & - & 67 & 100 & 33 \\
\hline$a_{31 n}$ & 778 & - & - & - & 18 & 30 & 12 \\
\hline$c_{3 l n}$ & 750 & - & - & - & - & 27 & - \\
\hline$d_{3 \ln }$ & 722 & - & - & - & 16 & 14 & 6 \\
\hline$e_{3 \ln }$ & 704 & - & - & - & 8 & 28 & 5 \\
\hline$g_{3 \mid n}$ & 676 & - & - & - & - & 30 & - \\
\hline${ }_{2} \mathrm{Og}$ & 563 & - & 79 & - & - & - & - \\
\hline $\mathrm{a}_{2 \mathrm{Og}}$ & 545 & - & 50 & - & - & - & - \\
\hline $\mathrm{c}_{2 \mathrm{Og}}$ & 517 & - & 19 & - & - & - & - \\
\hline $\mathrm{d}_{2 \mathrm{Og}}$ & 489 & - & 26 & - & - & - & - \\
\hline $\mathrm{e}_{2 \mathrm{Og}}$ & 471 & - & 18 & - & - & - & - \\
\hline $\mathrm{f}_{2 \mathrm{gg}}$ & 461 & - & 100 & - & - & - & - \\
\hline $\mathrm{h}_{2 \mathrm{Og}}$ & 429 & - & 11 & - & - & - & - \\
\hline${ }_{2} \ln$ & 549 & - & - & 100 & 100 & 85 & 19 \\
\hline$a_{2 \ln }$ & 531 & - & - & 16 & 11 & 10 & 5 \\
\hline$b_{2 \ln }$ & 517 & - & - & - & - & 8 & - \\
\hline $\mathrm{d}_{2 \ln }$ & 475 & - & - & 15 & 5 & 6 & - \\
\hline$e_{2 \ln }$ & 457 & - & - & - & - & 8 & - \\
\hline$f_{2 \ln }$ & 447 & - & - & 10 & 5 & 35 & 5 \\
\hline$g_{2 \ln }$ & 429 & - & - & - & - & 6 & - \\
\hline${ }_{1} \mathrm{Og}$ & 316 & 5 & - & - & - & - & - \\
\hline$a_{10 g}$ & 298 & 100 & - & - & - & - & - \\
\hline $\mathrm{b}_{10 \mathrm{~g}}$ & 284 & 36 & - & - & - & - & - \\
\hline $\mathrm{c}_{10 \mathrm{~g}}$ & 270 & 11 & - & - & - & - & - \\
\hline$d_{10 g}$ & 242 & 42 & - & - & - & - & - \\
\hline$e_{10 g}$ & 224 & 11 & - & - & - & - & - \\
\hline $\mathrm{f}_{1 \mathrm{Og}}$ & 214 & 21 & - & - & - & - & - \\
\hline${ }_{1} \ln$ & 302 & - & 86 & 19 & - & - & - \\
\hline
\end{tabular}

Table 3. (continued)

\begin{tabular}{lccccccc}
\hline \multicolumn{7}{c}{ Number of monosaccharide residues* } \\
\hline \hline & & \multicolumn{7}{c}{ Abundance [\%] } \\
\cline { 3 - 9 }$[\mathrm{M}+\mathrm{Na}]^{*}$ & $m / z$ & 1 & 2 & 3 & 4 & 5 & 6 \\
\hline \hline $\mathrm{a}_{1 \ln }$ & 284 & - & 30 & 9 & - & - & - \\
$\mathrm{b}_{1 \ln }$ & 270 & - & 5 & 5 & - & - & - \\
$\mathrm{d}_{1 \ln }$ & 228 & - & 5 & - & - & - & - \\
$\mathrm{e}_{1 \ln }$ & 210 & - & 7 & - & - & - & - \\
\hline
\end{tabular}

*The peak abundances under $5 \%$ are not included

Table 4. The ion abundances in ESI IT tandem mass spectra of $[\mathrm{M}+\mathrm{Na}]^{+}$ions of LPS models, serotype Inaba ${ }_{\mathbf{1}} \mathbf{I} \mathbf{n}_{-6} \mathbf{I} \mathbf{n}$

\begin{tabular}{|c|c|c|c|c|c|c|c|}
\hline \multicolumn{8}{|c|}{ Number of monosaccharide residues* } \\
\hline \multirow[b]{2}{*}[\mathrm{M}+\mathrm{Na}]{$^{+}$} & \multirow[b]{2}{*}{$m / z$} & \multicolumn{6}{|c|}{ Abundance [\%] } \\
\hline & & 1 & 2 & 3 & 4 & 5 & 6 \\
\hline${ }_{6} \ln$ & 1537 & - & - & - & - & - & 32 \\
\hline$a_{6}$ & 1519 & - & - & - & - & - & 100 \\
\hline$b_{6}$ & 1505 & - & - & - & - & - & 12 \\
\hline$c_{6}$ & 1491 & - & - & - & - & - & 23 \\
\hline$d_{6}$ & 1463 & - & - & - & - & - & 42 \\
\hline$e_{6}$ & 1445 & - & - & - & - & - & 5 \\
\hline$f_{6}$ & 1435 & - & - & - & - & - & 60 \\
\hline$g_{6}$ & 1417 & - & - & - & - & - & 6 \\
\hline${ }_{5} \mathrm{In}$ & 1290 & - & - & - & - & 43 & 61 \\
\hline$a_{5}$ & 1272 & - & - & - & - & 59 & 6 \\
\hline$c_{5}$ & 1244 & - & - & - & - & 10 & - \\
\hline$d_{5}$ & 1216 & - & - & - & - & 67 & 11 \\
\hline$f_{5}$ & 1188 & - & - & - & - & 40 & 5 \\
\hline${ }_{4} \ln$ & 1043 & - & - & - & 30 & 55 & 56 \\
\hline$a_{4}$ & 1025 & - & - & - & 53 & 11 & 6 \\
\hline $\mathrm{C}_{4}$ & 997 & - & - & - & 15 & 8 & 6 \\
\hline$d_{4}$ & 969 & - & - & - & 19 & 8 & 7 \\
\hline$f_{4}$ & 951 & - & - & - & 10 & 9 & 5 \\
\hline $\mathrm{f}_{4}$ & 941 & - & - & - & 23 & 11 & 9 \\
\hline$g_{4}$ & 923 & - & - & - & 12 & - & - \\
\hline${ }_{3} \ln$ & 796 & - & - & 37 & 100 & 100 & 44 \\
\hline$a_{3}$ & 778 & - & - & 24 & 9 & 11 & 5 \\
\hline$b_{3}$ & 764 & - & - & 11 & 5 & - & - \\
\hline$c_{3}$ & 750 & - & - & 10 & - & - & - \\
\hline$d_{3}$ & 722 & - & - & 12 & 7 & 13 & 17 \\
\hline$f_{3}$ & 694 & - & - & 17 & 15 & 5 & 18 \\
\hline${ }_{2}$ In & 549 & - & 15 & 32 & 92 & 52 & 19 \\
\hline$a_{2}$ & 531 & - & 16 & 100 & 3 & 18 & 24 \\
\hline$b_{2}$ & 517 & - & 10 & 6 & 9 & - & - \\
\hline$c_{2}$ & 503 & - & 47 & 12 & - & - & - \\
\hline$d_{2}$ & 475 & - & 22 & 16 & - & - & - \\
\hline$f_{2}$ & 447 & - & 68 & 43 & - & - & - \\
\hline \multirow[t]{2}{*}{$g_{2}$} & 429 & - & 95 & - & - & - & - \\
\hline & 330 & - & 11 & - & - & - & - \\
\hline${ }_{1} \ln$ & 302 & 17 & 12 & - & - & - & - \\
\hline$a_{1}$ & 284 & 100 & 100 & - & - & - & - \\
\hline$b_{1}$ & 270 & 12 & 6 & - & - & - & - \\
\hline$c_{1}$ & 256 & 16 & 6 & - & - & - & - \\
\hline $\mathrm{d}_{1}$ & 228 & 35 & 13 & - & - & - & \\
\hline$e_{1}$ & 210 & 11 & 5 & - & - & - & - \\
\hline$f_{1}$ & 200 & 13 & 5 & - & - & - & - \\
\hline
\end{tabular}

*The peak abundances under $5 \%$ are not included 


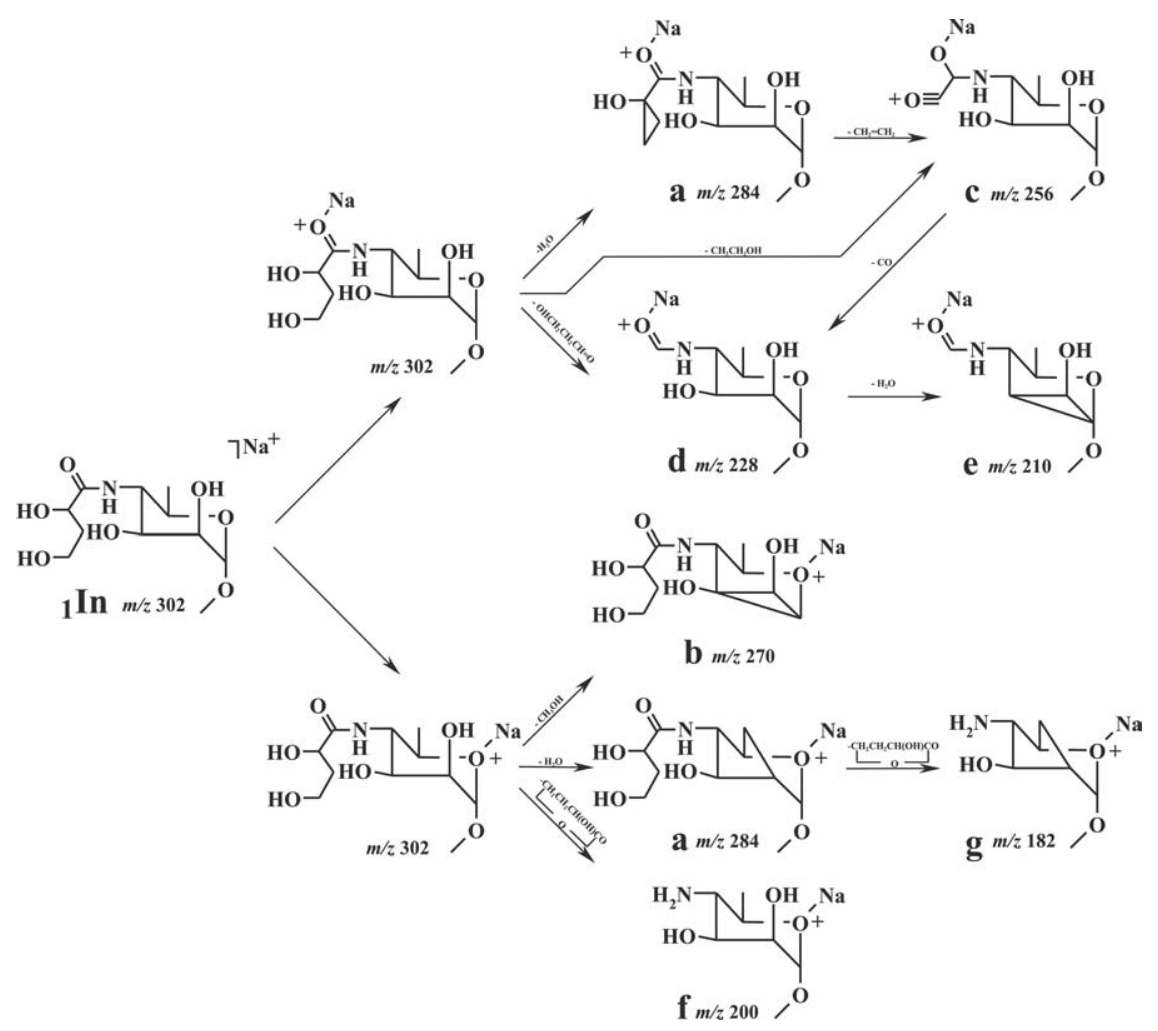

Scheme 1. The basic fragmentation mechanism pathways of the ${ }_{\mathbf{1}} \mathbf{I n}$ unit.

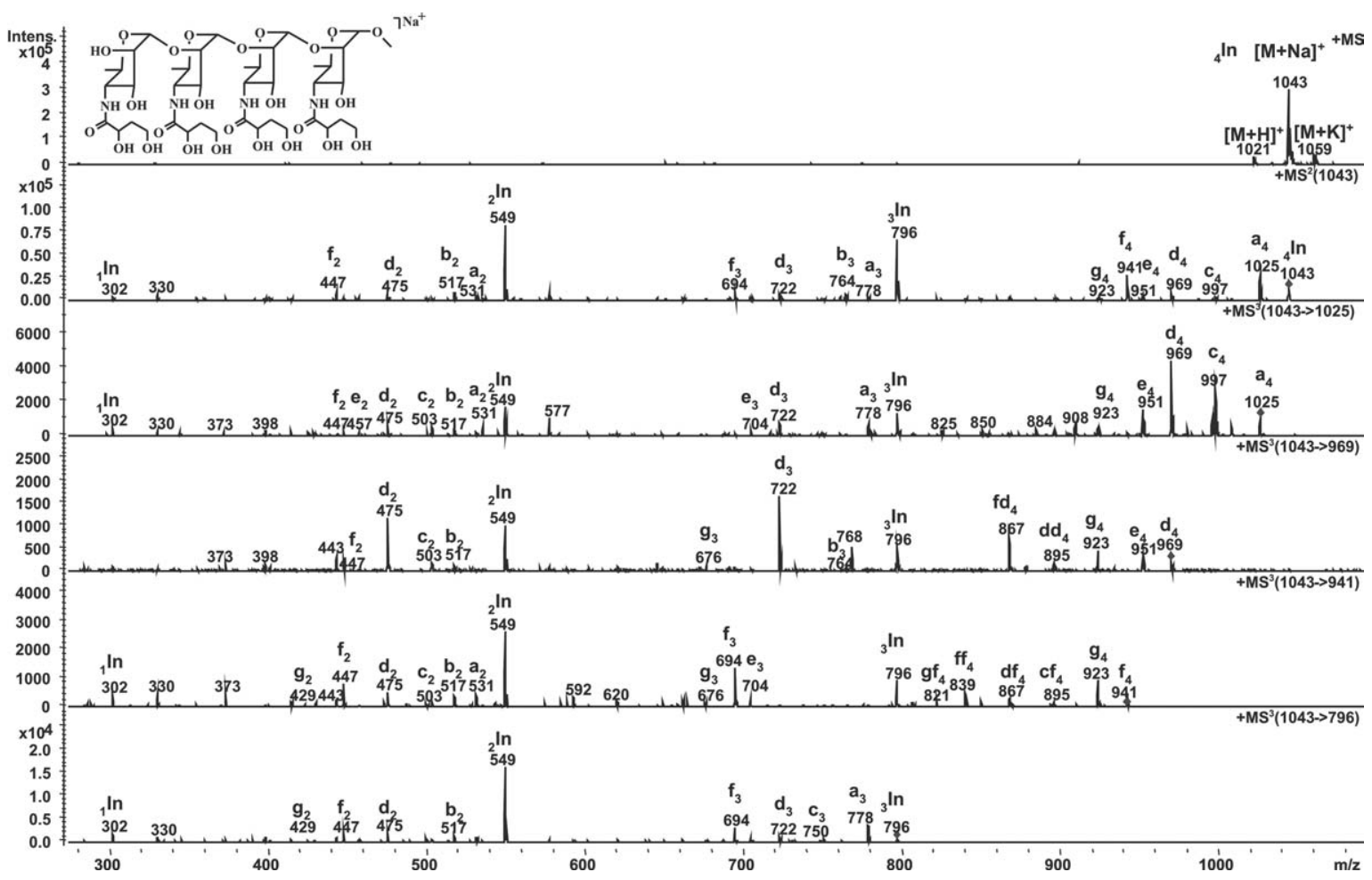

Figure 4. ESI IT multistage mass spectra of Inaba tetramer ${ }_{4}$ In. 


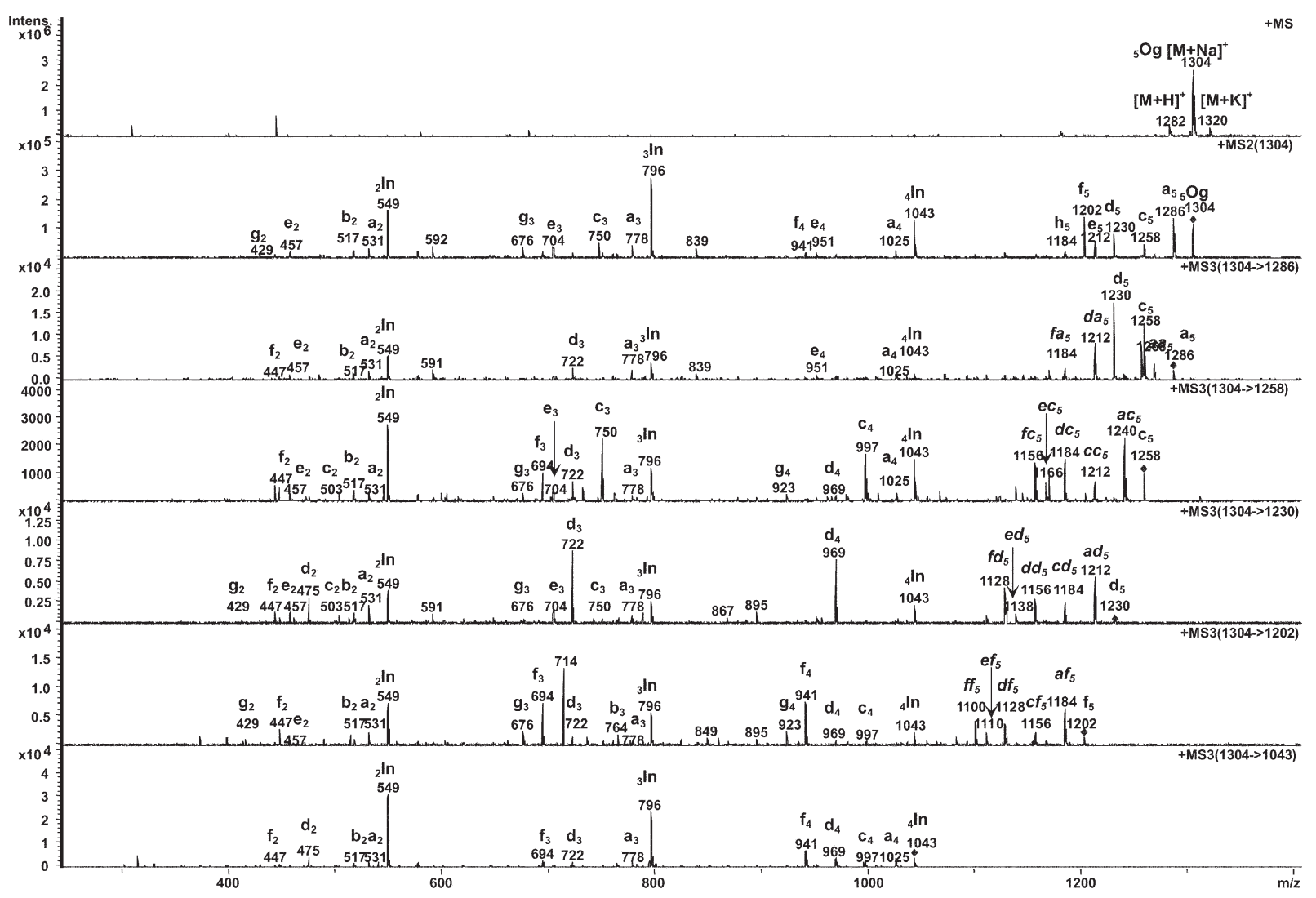

Figure 5. ESI IT multistage mass spectra of Ogawa pentamer ${ }_{5} \mathrm{Og}$.

Figure 4 show formation of $d a_{4}$ and $f a_{4}$ species equivalent to $\mathbf{e}$ and $\mathbf{g}$ ions in MS ${ }^{2}$ in the MS ${ }^{3}$ spectrum of $\mathbf{a}_{\mathbf{4}}$ ions, as well as of $c d_{4}, d d_{4}$, and $f d_{4}$ ions in the $\mathrm{MS}^{3}$ spectrum of $\mathbf{d}_{4}$. Similarly, the $a f_{4}, c f_{4}, d f_{4}$, and $f f_{4}$ species are visible in the $\mathrm{MS}^{3}$ fragmentation of $f_{4}$ ions. In the spectrum of the Ogawa pentamer ${ }_{5} \mathrm{Og}$ (Figure 5), the secondary ions $d a_{5}$ and $f a_{5}$ ions are visible at the MS ${ }^{3}$ fragmentation of $\mathbf{a}_{5}$ species, and $a c_{5}, c c_{5}, d c_{5}, e c_{5}$, and $f c_{5}$ are present in the fragmentation of $c_{5}$ product ions. Similarly, the $a d_{5}, c d_{5}, d d_{5}, e d_{5}$, and $f d_{5}$ fragments are produced in the fragmentation of $\mathbf{d}_{\mathbf{5}}$ ions, as well as the $a f_{5}, c f_{5}, d f_{5}, e f_{5}$, and $f f_{5}$ species arising from $\mathrm{f}_{5}$ ions. The mechanism of the formation of the ions under discussion is similar to that, described in Scheme $\mathbf{1}$.

\section{Conclusions}

The oligomeric models (mono- through hexasaccharide) of the O-antigens of Vibrio cholerae O:1 have been studied by electrospray ion trap multistage ( $\left.\mathrm{MS}^{\mathrm{n}}, n=1-3\right)$ mass spectrometry. The ESI IT technique has merits in that it provides information on the length of the repeating unit of the natural O-chain and his biological heterogeneity of $\mathrm{O}$-antigens from Vibrio cholerae LPS. In the first route, a molecule of water is eliminated from the sodium cationized molecular ion. In the following steps, elimination of a molecule of ethene, carbon monoxide, water, or 1-hydroxypropanal take place, as proven by $\mathrm{MS}^{2}$ and $\mathrm{MS}^{3}$ measurements. The fragmentation of hemi-acetal coordi- nated adducts involves elimination of a molecule of $\alpha$-hydroxy- $\gamma$-butyrolactone. The predominant pathway of fragmentation of the oligomers is the elimination shortening the length of the oligosaccharide. In this way, conversion of the Ogawa to Inaba fragments takes place under the conditions of measurement. Comparing various stages of multistage ESI IT mass spectra shows that the tandem $\mathrm{MS}^{2}$ spectra (Tables 3 and 4) are most informative for the structure elucidation of compounds of this type. The higher order ion trap spectra were found to be an excellent tool for the formulation of the fragmentation pathways.

\section{Acknowledgments}

This investigation was supported by VEGA grant no. 2/3159/23 of the Slovak Academy of Sciences and Ministry of Education of Slovakia.

\section{References}

1. Hisatsune, K.; Kondo, S.; Isshiki, Y.; Iguchi, T.; Haishima, Y. Occurrence of 2-O-Methyl-N-(3-deoxy-L-glycero-tetronyl)-D-Perosamine (4-Amino-4,6-dideoxy-D-mannopyranose) in Lipopolysaccharide from Ogawa but not from Inaba O-Forms of O:1, Vibrio cholerae. Biochem. Biophys. Res. Commun. 1993, 190, 302-307.

2. Ito, T.; Higuchi, T.; Hirobe, M.; Hiramatsu, K.; Yokota, T. Identification of a Novel Sugar, 4-Amino-4,6-dideoxy-2-O-ethyl-Mannose in the Lipopolysaccharide of Vibrio cholerae O:1 Serotype Ogawa. Carbohydr. Res. 1994, 256, 113-128.

3. Wang, J.; Villeneuve, S.; Zhang, J.; Lei, P.; Miller, C. E.; Lafaye, P.; Nato, F.; Szu, S. C.; Karpas, A.; Bystricky, S.; Robbins, J. B.; Kovac, P.; Fournier, J.-M.; Glaudemans, C. P. J. On the Antigenic Determinants of the Lipopolysaccharides of Vibrio cholerae O:1, Serotypes Ogawa and Inaba. J. Biol. Chem. 1998, 273, 2777-2783. 
4. Kenne, L.; Lindberg, B.; Unger, P.; Gustaffson, B.; Holme, T. Structural Studies of the Vibrio cholerae O-Antigen. Carbohydr. Res. 1982, 100, 341-349.

5. Kovacik, V.: Patoprsty, V.; Oksman, P.; Mistrík, R.; Kovac, P. Electron Ionization Mass Spectrometric Study of Monomeric Models of OPolysaccharides of Vibrio cholerae O:1, Serotypes Ogawa and Inaba. J. Mass Spectrom. 2003, 38, 924-930.

6. Matsuo, T.; Caprioli, R. M.; Gross, M. L.; Seyama, Y. Biological Mass Spectrometry, Present and Future; John Wiley and Sons: Chichester, Brisbane, Toronto, Singapore, 1995, pp 235-238.

7. Lei, P.-S.; Ogawa, Y.; Kovac, P. Synthesis of the Methyl $\alpha$-Glycosides of a Di-, Tri-, and Tetrasaccharide Fragment Mimicking the Terminus of the O-Polysaccharide of Vibrio cholerae O:1, Serotype Ogawa. Carbohydr. Res. 1996, 281, 47-60.

8. Zhang, J.; Kovac, P. Synthesis of Ligands Related to the Vibrio cholerae Specific Antigen. Part 14. Synthesis of Methyl D-Glycosides of Some Higher Oligosaccharide Fragments of Vibrio cholerae O1, Serotype Inaba and Ogawa. Carbohydr. Res. 1997, 300, 329-339.

9. Gotoh, M.; Kovac, P. Synthesis of the Methyl D-Glycoside of the Intracatenary Disaccharide Repeating Unit of the O-Polysaccharide of Vibrio cholerae O:1. A Comparison of Two Assembly Strategies. J. Carbohydr. Chem. 1994, 13, 1193-1213.

10. Lei, P.-S.; Ogawa, Y.; Kovac, P. Synthesis of the Methyl D-Glycoside of a Trisaccharide Mimicking the Terminus of the O-Antigen of Vibrio cholerae O:1, Serotype Inaba. Carbohydr. Res. 1995, 279, 117-131.
11. Ogawa, Y.; Lei, P.-S.; Kovac, P. Synthesis of a Functionalized Hexasaccharide Precursor of a Glycoconjugate Vaccine Against Cholera. Bioorg. Med. Chem. Lett. 1995, 19, 2283-2286.

12. Jaguar 5.5, Release 11, Schrödinger, Inc., Portland, OR, 2004.

13. Parallel Quantum Solutions, 2013 Green Acres, Suite A, Fayetteville, AR, 72703.

14. Becke, A. D. Density-Functional Thermochemistry. III. The Role of Exact Exchange. J. Chem. Phys. 1993, 98, 5648-5652.

15. Mistrik, R. Mass Frontier ${ }^{\mathrm{TM}}$ 4.0; http//www.highchem.com/

16. Kovacik, V.; Patoprsty, V.; Oksman, P.; Mistrik, R.; Kovac, P. Electron Impact Mass Spectrometric Study of Monomeric Models of Lipopolysaccharides of Vibrio cholerae O:1 Serotypes Ogawa and Inaba. Proceedings of the 50th ASMS Conference on Mass Spectrometry and Related Topics; Orlando, FL, June, 2002.

17. Fowler, P.; Bernet, B.; Vasella, A. A. ${ }^{1} \mathrm{H}-\mathrm{NMR}$ Spectroscopic Investigation of the Conformation of the Acetamido Group in Some Derivatives of N-Acetyl-d-Allosamine and -d-Glucosamine.Helv. Chim. Acta.792691996287

18. Kovacik, V.; Bekesova, S.; Tvaroska, I.; Hirsch, J.; Chmelik, J. Electrospray Ionization Ion-Trap Mass Spectrometric Study of Sodium Cationized Aldobiuronic and Pseudoaldobiuronic Acid Derivatives. J. Mass Spectrom. 2004, 39, 1554-1561.

19. Domon, B.; Costello, C. E. A. Systematic Nomenclature for Carbohydrate Fragmentations in FAB-MS/MS Spectra of Glycoconjugates. Glycoconj. J. 1988, 5, 397-409. 